\title{
Factorial invariance of the Adult State Hope Scale
}

\begin{tabular}{|c|c|}
\hline \multicolumn{2}{|l|}{$\begin{array}{l}\text { Authors: } \\
\text { Petrus Nel }{ }^{1} \\
\text { Adré Boshoff }{ }^{2}\end{array}$} \\
\hline \multicolumn{2}{|c|}{ 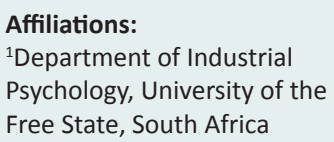 } \\
\hline \multicolumn{2}{|c|}{$\begin{array}{l}{ }^{2} \text { Department of Industrial } \\
\text { Psychology, University of the } \\
\text { Western Cape, South Africa }\end{array}$} \\
\hline \multicolumn{2}{|c|}{$\begin{array}{l}\text { Correspondence to: } \\
\text { Petrus Nel }\end{array}$} \\
\hline \multicolumn{2}{|c|}{$\begin{array}{l}\text { Email: } \\
\text { nelp1@ufs.ac.za }\end{array}$} \\
\hline \multicolumn{2}{|c|}{$\begin{array}{l}\text { Postal address: } \\
\text { PO Box 339, Bloemfontein } \\
9300 \text {, South Africa }\end{array}$} \\
\hline \multicolumn{2}{|c|}{$\begin{array}{l}\text { Dates: } \\
\text { Received: } 15 \text { Oct. } 2013 \\
\text { Accepted: } 26 \text { Feb. } 2014 \\
\text { Published: } 27 \text { May } 2014\end{array}$} \\
\hline \multicolumn{2}{|c|}{$\begin{array}{l}\text { How to cite this article: } \\
\text { Nel, P., \& Boshoff, A. (2014). } \\
\text { Factorial invariance of the } \\
\text { Adult State Hope Scale. } \\
\text { SA Journal of Industrial } \\
\text { Psychology/SA Tydskrif vir } \\
\text { Bedryfsielkunde, 40(1), Art. } \\
\# 1177,8 \text { pages. http:// } \\
\text { dx.doi.org/10.4102/sajip. } \\
\text { v40i1.1177 }\end{array}$} \\
\hline \multicolumn{2}{|c|}{$\begin{array}{l}\text { Copyright: } \\
\text { (C) 2014. The Authors. } \\
\text { Licensee: AOSIS } \\
\text { OpenJournals. This work } \\
\text { is licensed under the } \\
\text { Creative Commons } \\
\text { Attribution License. }\end{array}$} \\
\hline \multicolumn{2}{|l|}{ Read online: } \\
\hline aipra & $\begin{array}{l}\text { Scan this QR } \\
\text { code with your } \\
\text { smart phone or } \\
\text { mobile device } \\
\text { to read online. }\end{array}$ \\
\hline
\end{tabular}

Orientation: Given the interest in the impact of positive psychology on employees, it is imperative to use reliable and valid instruments to operationalise positive-psychology constructs. One such construct is hope.

Research purpose: The purpose of the study was to assess the degree of factorial invariance across race and gender by using a sample of aspiring chartered accountants.

Motivation for the study: Previous research on the hope construct and associated measuring instruments have been conducted, using homogenous samples from Westernised cultures. Researchers need to be careful to assume that hope looks and behaves in exactly the same manner across cultures and groups.

Research approach, design and method: A cross-sectional quantitative research design was used. A sample of 295 aspiring chartered accountants participated in the study. Exploratory factor analysis was used to determine the degree of factor similarity across groups, utilising Tucker's coefficient of congruence. To supplement the exploratory factor analysis, a series of increasingly restrictive multi-group analyses were conducted to test the invariance of model parameters across the groups.

Main findings: No significant differences were found in the factor patterns for the agency and pathways factors for (1) the white and designated groups and (2) females and males.

Practical/managerial implications: Evidence related to factorial invariance was found. This should inform researchers and practitioners that both pathways and agency look similar across racial and gender groups.

Contribution/value-add: Researchers are urged to use various statistical techniques, in combination, to determine the degree of factorial invariance across groups.

\section{Introduction}

The field of positive psychology is gaining prominence in the field Industrial and Organisational Psychology (Linley, Harrington \& Garcea, 2009). Internationally, the fields of positive organisational scholarship (Cameron, Dutton \& Quinn, 2003) and positive organisational behaviour (Luthans, 2002a; 2002b) are leading the way in applying positive-psychology constructs to the world of work. For example, Luthans (2002a, 2002b) suggests that positive organisational behaviour consists of the following constructs: self-efficacy, hope, optimism, resilience and emotional intelligence. Within the South African context, there has been a call to start investigating the impact of positive psychology on employees (Rothmann \& Cilliers, 2007). One construct that has been investigated within the South African context is hope and the role of hopeful leaders (Luthans, Van Wyk \& Walumba, 2004).

Snyder, Irving and Anderson (1991, p. 287) conceptualise hope as 'a positive motivational state that is based on an interactively derived sense of successful (a) agency (goal-directed energy), and (b) pathways (planning to meet goals)'. If South African researchers intend applying positive-psychology constructs (more specifically, hope) to the world of work, two issues need to be addressed: Firstly, they need to expand their understanding and conceptualisation of the hope construct. Secondly, they need to investigate the applicability of the operationalisation or measurement of hope within a South African context. Hence, is the Adult State Hope Scale that was developed in a Western culture applicable to the South African context?

In support of the second issue, Lopez, Snyder and Pedrotti (2003) state:

... the cross-cultural applicability of hope measures needs to be considered very carefully because the development and validation of research for the ... hope measures ... has been based on samples generally lacking diversity. (p. 103) 
They continued these sentiments by stating that researchers may be at risk if they assume that hope 'looks and behaves the same across all groups and cultures' (Lopez et al., 2003, p. 103). Similar sentiments are also echoed by Edwards, Rand, Lopez and Snyder (2007), emphasising the importance of determining the cross-cultural applicability of Snyder's conceptualisation and measurement of hope. In their argument, they emphasised both issues that South African researchers need to resolve before applying the Hope construct within the South African context.

\section{Research purpose and objectives}

To determine the cultural applicability of a measuring instrument (e.g. whether measurements represent identical constructs on identical scales), equivalence must be determined (Fontaine, 2008). Although Fontaine (2005) suggests different levels of equivalence, structural equivalence is what is important for the current study. Structural equivalence implies that 'the internal structure of the instrument shows correspondence across cultures' (Fontaine, 2008, p. 68). Therefore, the current study will determine the degree of factorial invariance of the Adult State Hope Scale across race and gender.

\section{Literature review}

Luthans et al. (2006) developed an instrument measuring psychological capital (PsyCap), operationalising the following constructs: efficacy, hope, optimism and resiliency. Although the construct hope is part of PsyCap, it is based on the conceptualisation of Snyder (1995, 2002). According to Snyder (2002), hope is primarily a way of thinking. Hope theory is based on the goal-directed thought processes of individuals. Individuals have goals and develop certain strategies to achieve those goals. In addition to these strategies, individuals also have different levels of motivation in using these strategies (Snyder, Rand \& Sigmon, 2005).

When confronting stressful situations (e.g. not achieving a stated goal), hope facilitates the individual's ability to find alternative paths to still achieve the goal as well as being motivated to using those paths. In essence, individuals choose the most appropriate path to still achieve their goal (Snyder et al., 2005).

\section{Pathways thinking}

Pathways thinking emphasises an individual's ability to produce alternative routes to a stated goal when goal achievement is being impeded. Pathways thinking also include positive self-talk about being able to produce alternative routes to the desired goal (Lopez et al., 2003; Snyder et al., 2005). Pathways thinking become important when individuals are faced with goal blockages. Highhope individuals are more likely to produce more than one pathway of reaching a particular goal with a sense of confidence in that route. High-hope individuals would be more decisive about the pathways for their goals (Snyder et al., 2005). Thus, high-hope individuals should be good at producing alternative routes to attain their goals, especially during impeding circumstances.

\section{Agency thinking}

The motivational component in hope theory resides with agency thinking (Snyder, 2002; Snyder et al., 2005). Individuals must have the perceived capacity to use one of the multiple pathways to achieve their goals, and individuals must be motivated to use the alternative pathways to achieve their goals when the latter are being blocked. This is especially important if individuals are faced with goal blockages - agency thinking helps individuals to direct their motivation to the most appropriate or alternative pathway (Snyder, 2002; Snyder et al., 2005).

\section{The relevance of hope for employees and organisations}

Luthans and Avolio (2003) suggest that leaders who have access to positive resources are in a much better position to develop as authentic leaders. In order to develop these positive resources, leaders must become more self-aware of their current levels of hope, optimism, confidence and resilience. For example, if a leader is unable or unwilling to recognise how lower levels of hope might affect their behaviour, they are more likely to continue to act in ways that discourage their followers' hope and performance. Hence, such leaders are not just negatively influencing their own development but also the development of their followers (Avolio, Griffith, Wernsing \& Walumbwa, 2010). There also seems to be a positive relationship between employees' levels of hope and organisational profitability (Adams et al., 2003). A positive relationship has also been found between leaders' levels of hope and the profitability of their units, the levels of satisfaction of their employees and the retention of their employees (Peterson \& Luthans, 2003). In addition, a large-scale survey found that the employees' and managers' levels of hope were positively related to performance, job satisfaction, happiness as well as organisational commitment (Youssef, 2004).

Hope has also been found to be a strong indicator of eustress amongst employees. In addition, hope at work is strongly related to both satisfaction with work and satisfaction with supervision (Simmons \& Nelson, 2007, p. 46). Research also seems to suggest that individuals who have the moral courage to speak out about ethical dilemmas in organisations may possess psychological strengths such as hope, efficacy, bravery, integrity, and optimism (Harrington \& Rayner, 2010). In addition, such individuals may also be high on selfawareness and self-regulation, the former being a component of authentic leadership (Mroz \& Quinn, 2010).

\section{Measuring hope}

In addition to using PsyCap's conceptualisation of hope, researchers can also use any of the different hope scales 
developed by Snyder and his colleagues (Snyder et al., 1991; Snyder et al., 1996). These include the Adult State Hope Scale (Snyder et al., 1996) and Adult Dispositional Hope Scale (Snyder et al., 1991).

The emphasis of the current study is the Adult State Hope Scale (Snyder et al., 1996). In four consecutive analyses, Snyder et al. (1996) successfully reproduced the twodimensional structure of the State Hope Scale with three items per factor. In all cases, factor analysis was conducted using principal component analysis with an oblique rotation (Snyder et al., 1996). The following quote summarises Snyder and his colleagues' (Snyder et al., 1996) findings regarding the psychometric properties of the Adult State Hope Scale:

It is internally consistent, yet the agency and pathways subscales are factorially identifiable as subcomponents of the overall measure. Also, these agency and pathways subscales exhibit high internal consistency, which is noteworthy given the fact that each subscale is based on only three items. (p. 334)

To date, both Snyder's Adult Hope Scale (Babyak, Snyder \& Yoshinobu, 1993; Edwards et al., 2007) and Adult Dispositional Scale (Roesch \& Vaughn, 2006) have been analysed using confirmatory factor analysis. The results of the Dispositional Hope Scale focused on the factorial validity within a multicultural American sample. During the development and validation of the Adult State Hope Scale, tentative findings regarding confirmatory factor analysis were presented - comparing various factor solutions (Snyder et al., 1996). The current study will therefore contribute to the psychometric evidence-based confirmatory factor analysis of the Adult State Hope Scale as well as providing evidence of the degree of factorial invariance across race and gender.

\section{Research design \\ Research approach}

In order to execute the research, the current study employed a cross-sectional design with a survey as data-collection technique.

\section{Research method}

\section{Research participants}

A total of 295 aspiring chartered accountants who had written one of their mandatory examinations participated in the study. Females $(n=161)$ were in the majority $(55 \%)$, compared to 134 males. Members from designated groups were in the minority (36\%), compared to 188 white individuals. The age for these participants ranged between 22 and 49 years $(\mathrm{M}=$ 27 ; $\mathrm{SD}=5)$. The majority of the sample was single $(n=213)$.

\section{Measuring instruments}

The Adult State Hope Scale has three agency and three pathways items to which respondents must respond in terms of how they are 'right now'. Individuals respond to the items using an eight-point scale ranging from $1=$ definitely false to $8=$ definitely true. Alphas range from 0.90 to 0.95 for the overall scale and 0.90 and higher for the agency and pathway factors on the State Hope Scale (Snyder et al., 1996).

\section{Research procedure and ethical clearance}

After the researchers had presented the research project and proposal to the Research Committees of both the Department and the Faculty, permission for the project and ethical clearance was granted. Permission was also obtained from the relevant professional body to approach the aspiring chartered accountants to participate in the study. A letter of invitation, with an electronic link to an online survey, was sent to those who had completed the compulsory professional exam. Research participants were informed that they were under no obligation to participate in the current study. They were also informed that their anonymity would be ensured. Finally, the participants were ensured that no individual results would be reported in any publications. Only aggregated data related to the whole group would be reported and discussed.

\section{Statistical analysis}

In order to determine the factorial invariance of the State Hope Scale across race and gender, the current study used both exploratory factor analysis and confirmatory factor analysis (Cheung \& Rensvold, 1999; Lorenzo-Seva \& ten Berge, 2006).

Initially, exploratory factor analysis was used as a basis for comparing the factor structure of the State Hope Scale across groups (Lorenzo-Seva \& Ten Berge, 2006). To determine the degree of equivalence of the factor structure across groups, Tucker's congruence coefficient (Tucker, 1951) was employed. This coefficient is calculated after one of the factor-loading matrices has been rotated to fit another factor-loading matrix by means of a Procrustes rotation. Two congruence levels were utilised to determine the degree of similarity of the factor loadings associated with the groups being compared (Lorenzo-Seva \& Ten Berge, 2006, p. 61): values between 0.85 and 0.94 can be interpreted as that the two factors compared are fairly similar whilst values higher than 0.95 are indicative of factors that have a good similarity.

However, Alwin and Jackson (1981, p. 250) is of the opinion that 'issues of factorial invariance are not adequately addressed using exploratory factor analysis'. To supplement the results of exploratory factor analysis, the current study also determined factorial structure by testing various hypotheses using multi-group confirmatory factor analysis. Given that the purpose of the current study is to determine whether the factorial structure is invariant across groups, Byrne (2006) suggests the following steps to be followed: Firstly, to what extent are the factor loadings invariant across groups? Secondly, are the variances invariant across the groups? Finally, to what extent are the covariances invariant across the groups? Hence, factorial invariance exists at various levels, depending on the outcome of three hypotheses (Cheung \& Rensvold, 1999). When items load on the same factor across groups (e.g. race or gender) and 
these factor loadings are not significantly different, there is evidence of factorial invariance. A higher level of invariance is evident when the variance-covariance matrices of the error terms are not statistically different across groups. According to Jöreskog and Sörbom (as cited by Cheung \& Rensvold, 1999 , p. 2), this is indicative of comparable reliability across the groups. The following level of invariance, in addition to the previous two levels, suggests that invariance is present when the variances of the latent variables are not statistically significant. Hence, the degree to which these three hypotheses are confirmed by the current study will give an indication of the level of invariance present across the groups (race and gender) with regards to the State Hope Scale. Although it may be useful, factorial invariance does not require testing for possible group differences in latent means or intercepts. The latter are not applicable in a construct validity study (Byrne, 2012).

However, invariance testing across groups assumes wellfitting, single-group models. This implies that the twodimensional model representing the State Hope Scale should demonstrate acceptable fit across the groups (Byrne, Shavelson \& Muthén, 1989).

All the analyses related to the confirmatory factor analysis were conducted using EQS 6.1 (Bentler, 2006). The data was treated as continuous. Through analysing the covariance matrix, the data was assessed for normality (Jackson, Gillaspy \& Purc-Stephenson, 2009). Mardia's coefficient was used to estimate multivariate normality (Bentler, 2006). On the basis of Mardia's coefficient of multivariate normality being bigger than five, the data was deemed skewed. The latter required the use of the robust maximum likelihood method of estimation. Several fit indices were used, including the Satorra-Bentler scaled chi-square, root mean square error of approximation (RMSEA), comparative fit index (CFI) and the McDonald fit index (MFI). Values close to 0.95 for CFI are considered indicative of good model fit. It is suggested that values close to 0.06 are indicative of acceptable fit for RMSEA. Finally, values close to 0.90 for MFI seem to be related to good fit (Hu \& Bentler, 1999). In addition, Akaike's information criterion (AIC) can be used when comparing competing models, with smaller values indicating the better fitting model (Byrne, 2006).

In estimating the reliability associated with the dimensions of the Adult State Hope Scale, Cronbach's alpha $(\alpha)$ was employed. Reliability estimates that are 0.7 and higher are indicative of good reliability. However, estimates as low as 0.6 may be acceptable when conducting exploratory research (Hair, Black, Babin, Anderson \& Tatham, 2006, pp. 137, 778).

\section{Results}

Table 1 reports the factor loadings associated with each of the two dimensions for the various groups (race and gender). There was a great deal of factor similarity between the two racial groups with regards to the pathways dimension (Tucker's phi $=0.98$ ). In addition, the agency dimension seems to be fairly similar between these two groups, with Tucker's phi being 0.99 . In short, both these dimensions have good similarity and can be considered as equal (LorenzoSeva \& Ten Berge, 2006, p. 61).

With regards to the pathways dimension, Tucker's phi was 0.98 between the female and male groups. The agency dimension seems to be fairly similar between these two groups, with Tucker's phi being 0.99 . Hence, both these dimensions have good similarity and can be considered as equal (Lorenzo-Seva \& Ten Berge, 2006, p. 61).

The reliability estimates reported in Table 2 are all above the acceptable level of 0.6. It should be noted that the groups differ with regards to the pathways dimension. Specifically, the white group has a lower estimate of reliability when compared to the designated group. This seems to be in line with the lower coefficient of congruence reported in Table 1. In addition, the female group has a lower estimate of reliability when compared to the male group. Again, this seems to be reflected by the fair degree of factor similarity reported in Table 1.

Table 3 provides information on the approximate fit indices associated with the two conceptualisations of the State Hope Scale. Although some of the indices indicate mediocre fit, others point to acceptable fit. What is worth noting is that the original two-dimensional structure provides a better fit to the data than the unidimensional structure, based on a lower value for AIC. Hence, it is this model that will be used for the multi-group analyses to test the invariance of model parameters across the groups.

TABLE 1: Factor loadings of the hope dimensions.

\begin{tabular}{lcccccc}
\hline Group & \multicolumn{5}{c}{ Dimension } \\
\cline { 2 - 7 } & .589 & .939 & .707 & .612 & .724 & .856 \\
Male & .396 & .683 & .782 & .621 & .757 & .793 \\
Female & .515 & .712 & .869 & .619 & .763 & .752 \\
Designated & .512 & .672 & .628 & .722 & .882 \\
White & .455 & .886 & .672
\end{tabular}

TABLE 2: Reliability estimates of the hope dimensions.

\begin{tabular}{lccc}
\hline Group & Pathways & Agency & Hope \\
\hline Female & 0.639 & 0.764 & 0.810 \\
Male & 0.781 & 0.772 & 0.834 \\
White & 0.698 & 0.784 & 0.808 \\
Designated & 0.734 & 0.753 & 0.846 \\
\hline
\end{tabular}

TABLE 3: Goodness-of-fit statistics of the hope construct (total group).

\begin{tabular}{lcc}
\hline Fit statistic & Two-dimensional structure & Unidimensional structure \\
\hline S-B $\chi^{2}$ & 33.8557 & 46.5554 \\
$d f$ & 8 & 9 \\
RMSEA & $0.105(0.070 ; 0.142)$ & $0.119(0.086 ; 0.154)$ \\
CFI & 0.932 & 0.902 \\
SRMR & 0.060 & 0.067 \\
MFI & 0.957 & 0.902 \\
AIC & 17.856 & 28.555 \\
\hline
\end{tabular}

S-B $\chi^{2}$, Satorra-Bentler scaled chi-square; $d f$, degrees of freedom; RMSEA, root mean square error of approximation; $\mathrm{CFI}$, comparative fit index; SRMR, standardised root mean square residual; MFI, McDonald's fit index; AIC, Akaike's information criterion 
Table 4 provides information on the approximate fit indices associated with the two-dimensional structure of the State Hope Scale across the various groups. It seems that the two-dimensional structure of the State Hope Scale produce a better fit with the data associated with the female and designated groups. The observed differences between gender and racial groups, with regards to goodness-of fit, need to be explored further by means of a multi-group confirmatory factor analysis.

The outcome of the three hypotheses tested in relation to factorial invariance with regards to race are reported in Table 5. It is clear that there are no significant changes in S-B $\chi^{2}$ when comparing the more constrained model with the less constrained model. These non-significant changes provide evidence related to the factorial invariance of the State Hope Scale with regards to race.

From Table 6, it is evident that the State Hope Scale shows evidence of factorial invariance with regards to gender. There are no significant changes in the values of the S-B $\chi^{2}$ when comparing the more constrained model with the less constrained model.

\section{Discussion}

The use of hope as a construct of investigation within the field of Industrial and Organisational Psychology is growing (Adams et al., 2003; Peterson \& Luthans, 2003; Youssef, 2004). If researchers intend to expand their understanding of the hope construct, the operationalisation of it becomes important. Hence, the psychometric properties associated with the choice of hope scale must be determined. In addition to determining the goodness-of-fit of the State Hope Scale associated with each group (race and gender), the factorial invariance of the State Hope Scale was also evaluated. The goal of the current study was to determine the factorial invariance of the State Hope Scale with regards to race and gender in a South African sample.

Before attempting to determine the degree of factorial invariance across race and gender, the current study first had to determine which conceptualisation of the State Hope Scale (two-dimensional versus unidimensional) was to be used for comparison purposes. Prior to the current study, the only other Hope Scales that were evaluated using confirmatory factor analysis was the Adult Hope Scale (Babyak et al., 1993; Edwards et al., 2007) and the Adult Dispositional Hope Scale (Roesch \& Vaughn, 2006). Evidence from tentative confirmatory factor analyses was provided by Snyder et al. (1996) related to the Adult State Hope Scale. From these studies, it became clear that the two-dimensional structure provided better fit to the data than the unidimensional structure. Roesch and Vaughn (2006) also found in their sample that the two-dimensional structure of the Adult Dispositional Scale provided a significantly better fit than the unidimensional model. The results of the South African sample support similar findings, with the two-dimensional structure exhibiting better fit than the unidimensional structure.

TABLE 4: Goodness-of-fit statistics of the hope construct across groups.

\begin{tabular}{lllllll}
\hline Group & S-B $\chi^{2}$ & $d f$ & RMSEA & CFI & MFI & 0.965 \\
Female & 19.4421 & 8 & $0.095(0.041 ; 0.148)$ & 0.938 & 0.054 \\
Male & 32.3026 & 8 & $0.151(0.099 ; 0.207)$ & 0.900 & 0.089 \\
White & 29.8141 & 8 & $0.121(0.076 ; 0.168)$ & 0.902 & 0.913 \\
Designated & 9.0325 & 8 & $0.035(0.00 ; 0.122)$ & 0.994 & 0.944 & 0.046 \\
\hline
\end{tabular}

S-B $\chi^{2}$, Satorra-Bentler scaled chi-square; $d f$, degrees of freedom; RMSEA, root mean square error of approximation; CFI, comparative fit index; SRMR, standardised root mean square residual; MFI, McDonald's fit index

TABLE 5: Multi-group confirmatory factor analysis Results (Race)

\begin{tabular}{|c|c|c|c|c|c|c|c|}
\hline Type of invariance & $\mathrm{ML} \chi^{2}$ & S-B $\chi^{2}$ & $d f$ & RMSEA & Model comparison & $\Delta \mathrm{S}-\mathrm{B} \chi^{2}$ & $p$ \\
\hline Unknown parameters are assumed to be different (Model 1 ) & 68.002 & 41.7112 & 16 & 0.105 & - & - & - \\
\hline Equal factor loadings (Model 2) & 69.584 & 43.6580 & 20 & 0.090 & 2 versus 1 & 1.0926 & 0.895 \\
\hline Equal factor loadings and covariances (Model 3) & 73.079 & 46.2907 & 21 & 0.091 & 3 versus 1 & 3.5915 & 0.609 \\
\hline Equal factor loadings, covariances, and variances(Model 4) & 77.519 & 49.9182 & 23 & 0.089 & 4 versus 1 & 6.9126 & 0.437 \\
\hline $\begin{array}{l}\text { Equal factor loadings, covariances, variances, and error variances } \\
\text { (Model 5) }\end{array}$ & 85.886 & 49.0496 & 29 & 0.069 & 5 versus 1 & 9.4324 & 0.739 \\
\hline
\end{tabular}

$\mathrm{ML} \chi^{2}$, maximum-likelihood chi-square; S-B $\chi^{2}$, Satorra-Bentler scaled chi-square; $d f$, degrees of freedom; RMSEA, root mean square error of approximation; $\Delta$ S-B $\chi^{2}$, change in Satorra-Bentler scaled chi-square; $p, p$-value

TABLE 6: Multi-group confirmatory factor analysis results (Gender).

\begin{tabular}{|c|c|c|c|c|c|c|c|}
\hline Type of invariance & $\mathbf{M L} \chi^{2}$ & S-B $\chi^{2}$ & $d f$ & RMSEA & Model comparison & $\Delta$ S-B $\chi^{2}$ & $p$ \\
\hline Unknown parameters are assumed to be different (Model 1 ) & 82.621 & 52.3822 & 16 & 0.125 & - & - & - \\
\hline Equal factor loadings (Model 2) & 86.305 & 53.6098 & 20 & 0.107 & 2 versus 1 & 2.1168 & 0.714 \\
\hline Equal factor loadings and covariances (Model 3 ) & 87.378 & 55.1672 & 21 & 0.106 & 3 versus 1 & 2.9638 & 0.705 \\
\hline Equal factor loadings, covariances, and variances (Model 4) & 91.077 & 57.6294 & 23 & 0.101 & 4 versus 1 & 5.326 & 0.620 \\
\hline $\begin{array}{l}\text { Equal factor loadings, covariances, variances, and error variances } \\
\text { (Model 5) }\end{array}$ & 93.329 & 55.2723 & 29 & 0.079 & 5 versus 1 & 5.3865 & 0.950 \\
\hline
\end{tabular}

$\mathrm{ML} \chi^{2}$, maximum-likelihood chi-square; S-B $\chi^{2}$, Satorra-Bentler scaled chi-square; $d f$, degrees of freedom; RMSEA, root mean square error of approximation; $\Delta$ S-B $\chi^{2}$, change in Satorra-Bentle scaled chi-square; $p$, $p$-value 
No significant differences were found for the designated and white groups in the factor structure for the pathways and agency factors. Using Tucker's coefficient of congruence, it was evident that both the designated and white groups had good factor similarity with regards to both the pathways and agency dimensions of the State Hope Scale. This is based on the fact that the congruence coefficients all exceeded 0.95 (Lorenzo-Seva \& Ten Berge, 2006, p. 61). Although both groups had acceptable levels of reliability associated with these two dimensions, the white group had a slightly lower level of reliability associated with the pathways dimension.

With a high degree of factor similarity, based on the results of exploratory factor analysis, the current study employed a multi-group confirmatory factor analysis to determine the degree of factorial invariance of the State Hope Scale with regards to race. It was evident that both the designated and white groups did not differ significantly with regards to factor loadings, covariances, variances and error variances. Hence, it is possible to state that the original two-factor solution shows evidence of factorial invariance across race.

A possible explanation for this finding may be the fact that the designated group used in the current study was a highly acculturated sample. Being busy with training to become chartered accountants and working in various organisations, there may have been minimal language and cultural constraints for these individuals with respect to reading and interpreting the items of the State Hope Scale.

No significant differences were found in the factor structure for the pathways and agency factors for the female and male groups. It was evident that both the female and male groups had good factor similarity with regards to both the pathways and agency dimensions of the State Hope Scale. This is based on the fact that the congruence coefficients all exceeded 0.95 (Lorenzo-Seva \& Ten Berge, 2006, p. 61). Although both these two groups had acceptable levels of reliability associated with these two dimensions, the female group had a lower level of reliability associated with the pathways dimension. It should be noted that Snyder et al. (1991) did not find any gender differences, albeit with the Dispositional Hope Scale. However, Snyder et al. (1996, pp. 332-333) concede that 'if there are goal-related activities for which men and women perceive themselves to be differentially affective, one would expect differences in state hope for those particular areas'. With Tucker's coefficient of congruence indicating a high degree of factor similarity between the two groups, the current study employed a multi-group confirmatory factor analysis to determine the degree of factorial invariance of the State Hope Scale with regards to gender. It was evident that both the designated and white groups did not differ significantly with regards to factor loadings, covariances, variances and error variances. Hence, it is possible to state that the original two-factor solution shows evidence of factorial invariance across gender.
Of concern is the relative poor fit in terms of RMSEA when looking at the goodness-of-fit of the State Hope Scale across the various groups. One possible explanation for this comes from Marsh and Bala (as cited by Marsh, Hau \& Grayson, 2005, p. 301). They found that the calculation of RMSEA is 'sensitive to model underparametrization'. The latter implies the possibility of model misspecification. The issue of model misspecification and its relationship with RMSEA was explored by Savalei (2012). It was suggested that the RMSEA may become lower when the model being tested is larger (Kenny \& McCoach, as cited by Savalei, 2012, p. 913). These authors found that RMSEA decreased as the number of indicators increased. Given that the Adult State Hope Scale only consists of six items, this may be one possible explanation for the large value of the RMSEA. In addition, $\mathrm{Hu}$ and Bentler (as cited by Savalei, 2012, p. 912) found that RMSEA was more sensitive to misspecified factor loadings than to misspecified factor correlations. It is therefore necessary to determine whether it may be theoretically possible for items correlating with the pathways dimension to also correlate with the agency dimension. Snyder et al. (1991) suggested that pathways and agency are distinct but highly correlated components. However, given the sensitivity of RMSEA to misspecified factor correlations, it may be necessary to determine whether individuals can distinguish between these two dimensions (Roesch et al., 2006, p. 82).

\section{Practical implications}

When using the State Hope Scale for research, investigators can be confident when using this instrument as a valid and reliable measure of both the pathways and agency dimensions of hope across race and gender. As a developmental tool, the State Hope Scale may also be quite useful. Since hope is regarded as a positive state-like psychological construct that is open to development (Youssef \& Luthans, 2007), this developmental nature of hope affords the opportunity to establish and implement individual-level interventions to focus on enhancing this resource. Individuals wishing to enhance their levels of hope should first establish the areas where they need to concentrate (pathways or agency). This can be achieved by completing a reliable and valid instrument in order to identify those strengths or shortcomings. On the basis of the results, hope interventions can be developed that may assist both employees and leaders to develop their levels of hope and authentic leadership. In addition, it may also enable employees to deal with stress and bullying and enhance their perceptions of job satisfaction.

With the results obtained from the State Hope Scale, employees are in a much better position to choose appropriate interventions to enhance their levels of hope given an accurate measure of their levels of hope. According to Lopez et al. (as cited in Lopez et al, 2004), the purpose of hope-enhancement strategies are:

... designed to help clients in conceptualizing clearer goals, producing numerous pathways to attainment, summoning the mental energy to maintain the goal pursuit, and reframing insurmountable obstacles as challenges to be overcome. (p. 393) 
Because most individuals have the cognitive capacity needed to generate a hopeful line of thought, it is possible to enhance this positive psychological strength (Lopez et al., 2004). To develop hopeful thinking, Lopez and his colleagues suggested four specific interventions, namely (1) hope finding, (2) hope bonding, (3) hope enhancing and (4) hope reminding (ibid:2004).

Luthans, Van Wyk and Walumba (2004, pp. 521-522) also suggest numerous interventions to develop hopeful leaders. For example, leaders can receive coaching and mentoring that integrates the four suggested interventions mentioned previously (e.g. hope finding, hope bonding, hope enhancing and hope reminding). Leaders can also enhance their levels of hope through self-reflection and developing skills to generate alternative paths when experiencing goal blockages. Finally, these authors urge researchers and practitioners to never forget that the suggested interventions should take cognisance of South Africa's history and various cultures before implementing hope-enhancing interventions.

When using psychological capital as the departure point to develop hope, Luthans, Youssef and Avolio (2007, pp. 68-72) suggest several interventions ranging from the development of goal-setting skills to the identification of resources that may help individuals to develop alternative pathways to achieve their goals.

\section{Limitations and recommendations}

Although the current study provides some insight into the structure of hope, both psychometric (i.e. measurement) and theoretical suggestions are put forward to improve future investigations.

To improve on the measurement op the hope construct, the following suggestions are put forward. Firstly, it is advisable to further investigate the factorial invariance of the Adult State Hope Scale amongst different language and racial groups in the South African context. It was not possible to validate the State Hope Scale in individual language and ethnic groups due to sample-size constraints. Secondly, there are more advanced statistical techniques, such as the Rasch analysis, that should be used to supplement the results obtained in the current study - especially in terms of differential item functioning. Finally, it is suggested that the factor structures obtained in the current study be crossvalidated using a different sample.

Although sound measurement properties associated with the State Hope Scale may improve future research, it is also necessary for researchers to build and investigate theories to explain the following phenomena (Carlsen, Hagen \& Mortensen, 2012). Firstly, research on hope needs to describe how hope is experienced by employees, how hope is shaped over time by organisational activities and how hope interacts with other organisational processes (such as organisational change and job crafting). Secondly, it may be worthwhile to develop theories to understand how organisations experience hope through various business cycles. For example, when organisations are faced with pursuing new business opportunities, emphasis is placed on the importance of imagination and hope. This may allow organisations to integrate appreciative inquiry and hope to pursue new possibilities.

\section{Conclusions}

The psychometric properties of the Adult State Hope Scale seem to be acceptable. The original two-factor structure of the hope construct fitted the data well - as evidenced by the overall goodness-of-fit statistics. The reliability associated with both the pathways and agency dimensions were acceptable across the various groups. No significant differences were found in the factorial patterns for the State Hope Scale and its two dimensions for (1) the designated and white group individuals and (2) females and males. The current study succeeded in showing that the factor-pattern coefficients for the two-factor structure of the State Hope Scale were robust and invariant across the various groups.

\section{Acknowledgements Competing interests}

The authors declare that they have no financial or personal relationship(s) that may have inappropriately influenced them in writing this article.

\section{Authors' contributions}

Both authors, P.N. (University of the Free State) and A.B. (University of the Western Cape) contributed equally to the writing of this article.

\section{References}

Adams, V.H., Snyder, C.R., Rand, K.L., King, E.A., Sigmon, D.R., \& Pulvers, K.M. (2003) Hope in the workplace. In R. Giacolone \& C. Jurkiewicz (Eds.), Handbook of workplace spirituality and organizational performance (pp. 367-377). New York: Sharpe.

Alwin, D.F., \& Jackson, D.J. (1981). Applications of simultaneous factor analysis issues to factorial invariance. In D.D. Jackson \& E.P. Borgatta (Eds.), Factor analysis and measurement in sociological research: A multidimensional perspective ( $\mathrm{pp} .249$ 280). Beverly Hills, CA: Sage

Avolio, B.J., Griffith, J., Wernsing, T.S., \& Walumbwa, F.O. (2010). What is authentic leadership development? In P.A. Linley, S. Harrington, \& N. Garcea (Eds.), Oxford handbook of positive psychology and work (pp. 39-52). New York, NY: Oxford University Press.

Babyak, M.A., Snyder, C.R., \& Yoshinobu, L. (1993). Psychometric properties of the Hope Scale: A confirmatory factor analysis. Journal of Research in Personality, 27, 154-169. http://dx.doi.org/10.1006/jrpe.1993.1011

Bentler, P.M. (2006). EQS 6 Structural Equations Program Manual. Multivariate Software, Inc. Encino, CA.

Byrne, B.M., Shavelson, R.J., \& Muthén, B. (1989). Testing the equivalence of factor covariance and mean structures: The issue of partial measurement invariance. Psychological Bulletin, 105, 456-466. http://dx.doi.org/10.1037/0033Psychological
2909.105.3.456

Byrne, B.M. (2006). Structural equation modelling with EQS: Basic concepts, applications and programming (2nd edn.). Mahwah, NJ: Erlbaum. http://dx.doi. org/10.1207/s15328007sem1302_7

Byrne, B.M. (2012). Structural equation modelling with Mplus: Basic concepts, applications and programming. New York, NY: Routledge.

Cameron, K.S., Dutton, J.E., \& Quinn, R.E. (2003). Positive organizational scholarship: Foundations of a new discipline. San Francisco, CA: Berret-Koehler Publishers.

Carlsen, A., Hagen, A.L., \& Mortensen, T.F. (2012). Imagining hope in organizations. In K.S. Cameron, \& G.M. Spreitzer (Eds.), The Oxford handbook of positive organizational scholarship (pp. 288-303). New York, NY: Oxford University Press.

Cheung, G.W., \& Rensvold, R.B. (1999). Testing factorial invariance across groups: A reconceptualization and proposed new method. Journal of Management, 25(1), 1-27. http://dx.doi.org/10.1177/014920639902500101 
Edwards, L.M., Rand, K.L., Lopez, S.J., \& Snyder, C.R. (2007). Understanding hope: A review of measurement and construct validity research. In A.D. Ong, \& M.H.M Van Dulmen (Eds.), Oxford handbook of methods in positive psychology (pp. 83Van Dulmen (Eds.), Oxford handbook of meth.
95). New York, NY: Oxford University Press.

Fontaine, J.R.J. (2005). Equivalence. In K. Kempf_Leonard (Ed.), Encyclopedia of social measurement (Vol. 1, pp. 803-813). San Diego, CA: Academic Press.

Fontaine, J.R.J. (2008). Traditional and multilevel approaches in cross-cultura research: An integration of methodological frameworks. In F.J.R. van de Vijver, D.A. van Hemert, \& Y.H. Poortinga (Eds.), Multilevel analysis of individuals and cultures (pp. 65-92). New York, NY: Lawrence Erlbaum Associates.

Hair, J.F., Black, B., Babin, B., Anderson, R.E., \& Tatham, R.L. (2006). Multivariate data analysis. (6th edn.). Upper Saddle River, NJ: Prentice Hall.

Harrington, S., \& Rayner, C. (2010). Look before you leap or dive right in? The use of moral courage in response to workplace bullying. In P.A. Linley, S. Harrington, \& N. Garcea (Eds.), Oxford handbook of positive psychology and work (pp. 265-276). New York, NY: Oxford University Press.

Hu, L., \& Bentler, P.M. (1999). Cutoff criteria for fit indexes in covariance structure analysis: Conventional criteria versus new alternatives. Structural Equation Modeling, 6, 1-55. http://dx.doi.org/10.1080/10705519909540118

Jackson, D.L., Gillaspy, J.A., \& Purc-Stephenson, R. (2009). Reporting practices in confirmatory factor analysis: An overview and some recommendations. Psychological Methods, 14, 6-23. http://dx.doi.org/10.1037/a0014694

Linley, P.A., Harrington, S. \& Garcea, N. (Eds.). (2009). Oxford Handbook of positive psychology and work. New York, NY: Oxford University Press.

Lopez, S.J., Snyder., C.R., Magyar-Moe, J.L., Edwards, L.M., Pedrotti, J.T., Janowski, K., Turner, J.L., \& Pressgrove, C. (2004). Strategies for accentuating hope. In P.A Linley \& Joseph, S. (Eds.), Positive psychology in practice (pp. 388-404). Hoboken, New York: John Wiley \& Sons.

Lopez, S.J., Snyder, C.R., \& Pedrotti, J.T. (2003). Hope: Many definitions, many measures. In S.J. Lopez \& C.R. Snyder (Eds.), Positive psychological assessment A handbook of models and measures (pp. 91-108). Washington, DC: American Psychological Association. http://dx.doi.org/10.1037/10612-000

Lorenzo-Seva, U., \& Ten Berge, J.M.F. (2006). Tucker's congruence coefficient as a meaningful index of factor similarity. Methodology, 2, 57-64.

Luthans, F. (2002a). Positive organizational behavior: Developing and managing psychological strengths. Academy of Management Executive, 16, 57-75. http:// dx.doi.org/10.5465/AME.2002.6640181

Luthans, F. (2002b). The need for and meaning of positive organizational behavior Journal of Organizational Behavior, 23, 695-706. http://dx.doi.org/10.1002/ job.165

Luthans, F., Avey, J.B., Avolio, B.J., Norman, S., \& Combs, G.M. (2006). Psychological capital development: A micro intervention. Journal of Organizational Behavior 27, 387-393. http://dx.doi.org/10.1002/job.373

Luthans, F., \& Avolio, B. (2003). Authentic leadership development: A positive development approach. In K.S. Cameron, J.E, Dutton \& R.E. Quinn (Eds.), Positive organizational scholarship (pp. 241-258). San Francisco: Berrett-Koehler.

Luthans, F., Van Wyk, R., \& Walumba, F.O. (2004). Recognition and development of hope for South African organizational leaders. The Leadership \& Organization Development Journal, 25, 512-527. http://dx.doi. org/10.1108/01437730410556752

Luthans, F., Youssef, C.M., \& Avolio, B.J. (2007). Psychological capital: Developing the human competitive edge. New York, NY: Oxford University Press.
Marsh, H.W., Hau, K., \& Grayson, D. (2005). Goodness of fit in structural equation models. In A. Maydeu-Olivares \& J.J. McArdle (Eds.) Contemporary psychometrics (pp. 275-340). Mahwah, New Jersey: Lawrence Erlbaum Associates.

Mroz, D., \& Quinn, S. (2010). Positive organizational scholarship leaps into the world of work. In P.A. Linley, S. Harrington, \& N. Garcea (Eds.), Oxford handbook of positive psychology and work (pp. 251-264). New York, NY: Oxford University Press.

Peterson, S.J., \& Luthans, F. (2003). The positive impact and development of hopeful leaders. Leadership and Organization Development Journal, 24, 26-31. http:// dx.doi.org/10.1108/01437730310457302

Roesch, S.C., \& Vaughn, A.A. (2006). Evidence for the factorial validity of the Dispositional Hope Scale. European Journal of Psychological Assessment, 22, 78-84. http://dx.doi.org/10.1027/1015-5759.22.2.78

Rothmann, S., \& Cilliers, F.V.N. (2007). Present challenges and some critical issues for research in industrial/organisational psychology in South Africa. SA Journal of Industrial Psychology, 33, 8-17. http://dx.doi.org/10.4102/sajip.v33i1.262

Savalei, V. (2012). The relationship between Root Mean Square Error of Approximation and model misspecification in Confirmatory Factor Analysis models. Educational and Psychological Measurement, 72, 910-932. http://dx.doi. org $/ 10.1177 / 0013164412452564$

Simmons, B.L., \& Nelson, D.L. (2007). Eustress at work: Extending the holistic stress model. In D.L. Nelson, \& C.L. Cooper (Eds.), Positive organizational behavior (pp. 40-54). London: Sage Publications. http://dx.doi.org/10.4135/9781446212752. $\mathrm{n} 4$

Snyder, C.R. (1995). Conceptualizing, measuring, and nurturing hope. org/10.1002/j.1556-6676.1995.tb01764.x

Snyder, C.R. (2002). Hope theory: Rainbows in the mind. Psychological Inquiry, 13, 249-275. http://dx.doi.org/10.1207/S15327965PLI1304_01

Snyder, C.R., Harris, C., Anderson, J.R., Holleran, S.A., \& Irving, L.M. (1991). The wil and the ways: Development and validation of an individual-differences measure of hope. Journal of Personality and Social Psychology, 60, 570-585. http://dx.doi. org/10.1037/0022-3514.60.4.570

Snyder, C.R., Irving, L., \& Anderson, J.R. (1991). Hope and health: Measuring the will and the ways. In C.R. Snyder \& D.R. Forsyth (Eds.), Handbook of social and clinical psychology: The health perspective (pp. 285-305). Elmsford, NY: Pergamon.

Snyder, C.R., Rand, K.L., \& Sigmon, D.R. (2005). Hope theory: A member of the positive psychology family. In C.R. Snyder \& S.J. Lopez (Eds.), Handbook of positive psychology (pp. 257-276). New York, NY: Oxford University Press.

Snyder, C.R., Sympson, S.C., Ybasco, F.C., Borders, T.F., Babyak, M.A., \& Higgins, R.L. (1996). Development and validation of the State Hope Scale. Journal of Personality and Social Psychology, 70, 321-335. http://dx.doi.org/10.1037/0022 3514.70.2.321

Tucker, L.R. (1951). A method for synthesis of factor analysis studies (Personnel Research Section Report No. 984). Washington, DC: Department of the Army

Youssef, C.M. (2004). Resilience development of organizations, leaders and employees: Multi-level theory building and individual-level, path-analytical empirical testing. Unpublished doctoral dissertation, University of Nebraska-Lincoln, United States of America.

Youssef, C.M., \& Luthans, F. (2007). Positive organizational behaviour in the workplace: The impact of hope, optimism and resilience. Journal of Management, 33, 774800. http://dx.doi.org/10.1177/0149206307305562 